\title{
Does the Shape of the L5 Vertebral Body Depend on the Height of CT Slices in the Pedicle?
}

\author{
Evaluation of the Shape of the L5 Vertebral Body With a \\ Multicut CT Scan
}

Matias Alfonso, MD, PhD,* Patricia Palacio, MD, $\dagger$ Gorka Bastarrika, MD, PhD, $\ddagger$ and Carlos Villas, MD, $\mathrm{PhD}^{*}$

From the *Orthopedic Surgery Department, University Clinic of Navarra; †C.S. Rochapea; and $\ddagger$ Radiology Department, University Clinic of Navarra, Pamplona, Spain.

Address correspondence and reprint requests to Matias Alfonso Olmos, MD, PhD, University Clinic of Navarra, Orthopaedic Surgery Department, Avda Pio XII, 36 Pamplona, Spain; E-mail: malfonsool@ unav.es

\section{ABSTRACT}

Study Design: The shape of the L5 vertebral body was analyzed using a computerized tomography (CT) scan.

Objective: The aim of this study is to determine if the vertebral L5 body shape varies depending on the height of the CT slices through the L5 pedicle.

Summary of Background Data: The morphometry of L5 has been studied to help the introduction of pedicular screws. The shape of the vertebral body has been seldom looked into, and the findings obtained show a triangular shape and hemispherical shape, supposedly owing to interpersonal variability. The hemisphere shape enables pedicular screws to be introduced nonconvergently, whereas the triangular shape enables pedicular screws to be introduced at a convergent angle but posing the risk of cortical perforation unless these guidelines are followed.

Methods: Abdominal CT multicut with 64 crowns was performed in 101 consecutive patients with diverse indications. Width of CT slices was with a 1-mm reconstruction increase. We selected one axial slice that passed through the upper part of the pedicle and another one that passed through the lower part of the pedicle and compared next parameters in both cuts: pedicular cortical width, pedicular endostal width, pedicular angle, vertebral body length, vertebral body width, vertebral perimeter angles, and visual appearance of vertebral body shape.

Results: We found statistical differences between all values except the anterior vertebral perimeter angle on comparing values of upper part with values of lower part and visual vertebral body shape was different in $93 \%$ of vertebrae. In the upper part the vertebral body is hemispherical whereas in the lower part it is triangular.

Conclusion: In most cases, the vertebral body shape is hemispherical in the upper part of the pedicle and triangular in the lower part of the pedicle. It means that in the lower part pedicular screws must be introduced at a more convergent angle than in the upper part if we do not want to break any cortical of the vertebral body.

Key words: vertebral shape, morphometry, LS vertebra. 


\section{INTRODUCTION}

Several studies have been conducted to determine the morphometry of lumbar vertebrae $^{1-3}$ and thus help the introduction of pedicular screws and cages. These studies have been carried out using fresh cadavera, ${ }^{4-6}$ osteologic collections, ${ }^{2,7}$ and more recently, in computerized tomography (CT) images. ${ }^{8-11}$ The most frequently analyzed parameters are the pedicular width and pedicular endostal width (PEW), pedicular angle (PA), dimensions of the canal, vertebral body length (VBL), and vertebral body height. These findings have set the guidelines so as to establish the length and width of pedicular screws allowed in each lumbar vertebral level.

The shape of the vertebral body of lumbar vertebrae has been seldom studied. By means of a CT scan Van Schaik et al ${ }^{12}$ examined its shape by tracing a line along the outer border of the vertebral body. In L5, the shape of the body was triangular and a unique angle contouring the external cortical of vertebral body measured 53 degrees. In research work performed by Alfonso et $\mathrm{al}^{13}$ using CT, we observed 2 types of L5 vertebrae and supposed it was because of interpersonal variability. These types were triangular and hemispherical. The hemisphere shape would allow 45-mm long pedicular screws to be introduced nonconvergently from back to front and even longer ones if we converged the screws. On the other hand, triangular shape would allow 45-mm long pedicular screws with a convergent angle or a 40-mm long nonconvergent screw. In triangular L5 vertebra, the risk of cortical perforation would be high if we did not follow these guidelines.

Following this research we considered that the shape of L5 could be varied depending on the height of CT slices in the pedicle. Therefore, upper slices through the pedicle could show a different shape of the L5 vertebral body than lower cuts through that very same pedicle.

\section{PATIENTS AND METHODS}

Abdominal CT was conducted in 146 consecutive patients with diverse indications. The system is a last generation CT multicut with 64 crowns, Siemens Sensation 64 (Erlagen, Germany). The width of the CT slices was $1 \mathrm{~mm}$ with a $1 \mathrm{~mm}$ increase of reconstruction. Image reconstruction was obtained through the Leonardo of Siemens system. A bone filter was used. CT slices were made parallel to superior vertebral endplates each and every $1 \mathrm{~mm}$.

Axial slices were obtained as well as sagittal and coronal reconstructions. We selected one axial slice that passed through the upper part of the pedicle whereas another one passed through the lower part of the pedicle (Figure 1).

Inclusion criteria of patients were aged between 18 and 60 and without any previous pathology in the L5 vertebra. Exclusion criteria were transitional vertebra, pathology of L5 (infection, fracture, or tumor), or aged under 18 or above 60.

Parameters measured in the axial CT slices were:

1. Pedicular cortical width (PCW): distance between the outer medial cortical and outer lateral cortical of the pedicle (Figures 2A, B). 
2. PEW: distance between the inner medial cortical and inner lateral cortical of the pedicle (Figures 2A, B).

3. PA: angle between a line that passes through the center of the pedicle following its axis and a line that passes though the posterior part of the vertebral body.

4. VBL: distance between the outer part of the anterior border and posterior border of the vertebral body (Figures 2A, B).

5. Vertebral body width at $100 \%\left(\mathrm{VBW}_{100 \%}\right)$ : width of the vertebral body in the most posterior part (Figures 3A, B).

6. VBW at $50 \%\left(\mathrm{VBW}_{50 \%}\right)$ : width of the vertebral body in the $50 \%$ of its length (Figures 3A, B).

7. VBW at $25 \%\left(\mathrm{VBW}_{25 \%}\right)$ : width of the vertebral body in the anterior $25 \%$ of its length (Figures 3A, B).

8. Vertebral perimeter angle (VPA): 2 angles were measured attempting to classify the shape of the vertebral body objectively. $\mathrm{VPA}_{1}$ is the angle between a line that passes through the posterior part of the vertebral body and a line along the cortical border up to the junction of the $\mathrm{VBW}_{50 \%}$ line with the cortical of the vertebra (Figures $3 \mathrm{~A}, \mathrm{~B}$ ). $\mathrm{VPA}_{2}$ is the angle between the $\mathrm{VBW}_{50 \%}$ line and a line along the cortical border up to the junction of the $\mathrm{VBW}_{25 \%}$ line with the cortical of the vertebra (Figures 3A, B).

9. Shape of vertebral body: hemispherical (Figure 4A) and triangular (Figure 4B).

PCW, PEW, and PA parameters were measured in every vertebra on the right pedicle and left pedicle in 2 axial cuts: an axial cut that passed through the upper part of the pedicle and another one that passed through the lower part of the pedicle.

VBL, VBW $100 \%, \mathrm{VBW}_{50 \%}, \mathrm{VBW}_{25 \%}, \mathrm{VPA}_{1}, \mathrm{VPA}_{2}$ parameters were measured in every vertebra in 2 axial CT slices: an axial slice that passes by the upper part of the pedicle and another one that pass by the lower part of the pedicle.

Statistical analysis comparing the groups is conducted with the paired Student t test in measures in the same patient (comparing upper part and lower part).

\section{RESULTS}

One hundred one patients met inclusion criteria(46 men and 55 women). Results are showed in Table 1 and Table 2.

The vertebral shapes were compared in the upper and lower parts of the pedicle in each patient showing visual differences. Most of the vertebrae (94 vertebrae) showed substantial visual differences: the upper vertebral slices acquiring a hemispherical shape whereas the shape of the lower part was triangular (93.06\%) (Figures 4A, B). In 7 vertebrae the visual differences were not significant.

All the findings revealed significant differences when comparing the upper part of the pedicle with the lower part except for the $\mathrm{VPA}_{2}$ value. 


\section{DISCUSSION}

The L5 vertebra, just as in the case of the S1, possess difficulties when it comes to applying pedicular screws because of its inclination in the sagittal plane and the orientation and angle of its pedicles that often make it difficult to introduce them convergently. Results obtained in this study show a difference between the vertebral body shape in the upper and lower part of pedicle. Pedicles are wider (both endostal and cortical width) in the upper part, both in right and left hand sides. The PA is more convergent in the lower part, both on the right and left hand sides. VBL is higher in the upper part than in the lower part. The VBW is wider in the lower part in the most posterior part of vertebral body $\left(\mathrm{VBW}_{100 \%}\right)$ but in $\mathrm{VBW}_{50 \%}$ and $\mathrm{VBW}_{25 \%}$ is wider in the upper part. The $\mathrm{VPA}_{1}$ is more convergent in the lower part of pedicle and the $\mathrm{VPA}_{2}$ is similar in the lower and upper parts, not showing statistical differences. The difference in the $\mathrm{VBW}_{100 \%}, \mathrm{VBW}_{50 \%}, \mathrm{VBW}_{25 \%}$, and $\mathrm{VPA}_{1}$ ends in the hemispheric shape in upper part and triangular shape in the lower part in most of cases (93\%). Therefore, a screw placed in the superior part of the pedicle and near the superior endplate in the vertebral body can be introduced with a slight angle without risk of going through the anterior cortical. However, if we introduce the screw in the lower part of the pedicle and if it is housed in the vertebral body far from the endplate, we must introduce it with a 45 degree angle otherwise the screw will go through the anterior cortical of the vertebra, possibly putting the neurovascular structures at risk. It also depends on the length of the screws, and therefore a 45-mm long screw in the lower part of pedicle must be introduced at a greater angle than a $40-\mathrm{mm}$ long screw in the lower part of pedicle. In the upper part it is not so important but we have to bear it in mind. Research work conducted by Beguiristain et $\mathrm{al}^{14}$ found that $100 \%$ of screws over $50 \mathrm{~mm}$ went through vertebral cortex anteriorly.

Lesions of neurovascular structures are not common but a screw inside the vertebral body is unable to cause any damage to nerve roots or vessels. The L 4 roots are in the lateral part of the vertebral body and a screw which is at least $45 \mathrm{~mm}$ long and it is not introduced with an angle in the inferior part of the pedicle could break the lateral cortical and come into contact with the L4 root and damage it. Jendrisak ${ }^{15}$ reported a case of spontaneous rupture of the aorta because of an anterior implant and Vanichkachorn et $\mathrm{al}^{16}$ reported a case of an implant removal because of the implant protrusion which affected the aorta. Lim et $\mathrm{al}^{17}$ reported a case of pseudoanaeurism of the aorta after an instrumentation with pedicular screws in T12 and L3. On the other hand, Asprinio and Curcin ${ }^{18}$ suggested that the low incidence of vascular lesions is due to the protection of anterior vertebral ligament. In their study they introduced pedicular screws from L1 to L5 passing $5 \mathrm{~mm}$ from the anterior cortex and no screw crossed the ligament. However, we have observed screws that were inserted over $5 \mathrm{~mm}$ and came into contact with the iliac veins, arteries, and L4 roots.

Some authors prefer to go through the anterior cortical as the pull-out strength is increased, ${ }^{19}$ even though Lavaste's ${ }^{20}$ findings did not suggest significant differences concerning the pull-out strength between going through the anterior cortex or not. It could be interesting in cases with osteoporosis but in patients with good bone mass it is not required. In the upper part of the pedicle we can introduce, in a perpendicular way, longer screws than in the lower part of the pedicle increasing pull-out strength ${ }^{19}$ in patients with good bone mass. Using screws longer than $40 \mathrm{~mm}$ in a perpendicular direction in the lower part of the pedicle, we could perforate the cortical increasing the 
risk of lesion the neurovascular structures, even though it would not decrease pull-out strength.

Our findings are similar to those obtained in research on PCW, PEW. and VIIL carried out with CT by other authors. ${ }^{4,8-10}$ Regarding PA, results in research led by $\mathrm{Sim}^{22}$ were similar although varying slightly with those obtained by other authors. ${ }^{9,10}$ The $\mathrm{VPA}_{1}$ and $\mathrm{VPA}_{2}$ values have not been studied by other authors to our knowledge. Concerning Van Schaik et $\mathrm{al}^{12}$ research, on L5 vertebrae presenting a triangular shape, we believe that the CT cuts were in the inferior part of the pedicle.

Considering these findings our recommendations regarding the insertion of pedicular screw in L5 vertebra are as follows:

- In the upper part of pedicle a 45-mm long screw can be introduced at a slight angle (10 degrees) or a $40-\mathrm{mm}$ long screw can be inserted perpendicularly (straight from posterior to anterior) without any risk to penetrate the anterior or lateral vertebral body.

- In the lower part of the pedicle a $40-\mathrm{mm}$ long screw can be inserted at 20 degrees to 30 degrees angle. However, a 45-mm long screw should be placed at a 45 degrees to 50 degrees angle to avoid penetrating the anterior or lateral vertebral body.

\section{REFERENCES}

1. Bernhardt M, Swarzt DE, Clothiaux RL, et al. Posterolateral lumbar and lumbosacral fusion with and without pedicle screw internal fixation. Clin Orthop Relat Res 1992;284:109-19.

2. Berry J, Moran J, Berg W, et al. A Morphometric study of human lumbar and selected thoracic vertebrae. Spine 1987;12:362-7.

3. Postacchini F, Ripani M, Carpano S. Morphometry of the lumbar vertebrae. Clin Othop Relat Res 1983;172:296-303.

4. Misenhimer G, Peek R, Wiltse L, et al. Anatomic analysis of pedicle cortical and cancellous diameter as related to screw size. Spine 1989;14:367-72.

5. Panjabi MM, Goel V, Oxland T, et al. Human lumbar vertebrae: cuantitative three-dimensional anatomy. Spine 1992;17:299-306.

6. Saillant G. Étude anatomique des pédicules vertébraux. Application chirurgicale. Rev Chir Orthop 1976;62:151-60.

7. Olsewski J, Simmons E, Kallen F, et al. Morphometry of lumbar spine: anatomical perspectives related to transpedicular fixation. J Bone Joint Surg Am 1990;72:541-9.

8. Bernard T, Seibert C. Pedicle diámeter determined by computed tomography. Its relevance to pedicle screw fixation in the lumbar spine. Spine 1992; 17(suppl):S160-S163.

9. Cheung K, Ruan D, Chan F, et al. Computed tomographic osteometry of asian lumbar pedicles. Spine 1994;19:1495-8.

10. Krag M, Weaver D, Beynnon B, et al. Morphometry of the thoracic and lumbar spine related to transpedicular screw placement for surgical spinal fixation. Spine 1988;13:27-32.

11. Zindrick MR, Wilste LL, Doornik A, et al. Analysis of the morphometric characteristics of the thoracic and lumbar pedicles. Spine 1987;12:160-6. 
12. Van Schaik J, Verbiest H, Van Schaik F. Morphometry of lower lumbar vertebrae as seen on CT scans: newly recognized characteristics. AJR Am J Roentgenol 1985;145:327-35.

13. Alfonso M, Villas C, Beguiristain JL, et al. Morfometría vertebral en población española. Rev Ortop Traumatol 2002;46:158-64.

14. Beguiristain JL, Berjano P, Alfonso M, et al. Valoración por tomografía axial computadorizada de la posición de tornillos pediculares en raquis lumbosacro. Rev Ortop Traumatol 2001;45:106-13.

15. Jendrisak M. Spontaneous abdominal aortic rupture from erosion by a lumbar spine fixation device: a case report. Surgery 1986;18:2327-31.

16. Vanichkachorn J, Vaccaro A, Cohen M, et al. Potential large vessel injury during thoracolumbar pedicle screw removal. A case report. Spine 1997;22: 110-13.

17. Lim K, Fan K, Wong Y, et al. Iatrogenic upper abdominal aortic injury with pseudoanaeurism during spinal surgery. J Trauma 1999;46:729-31.

18. Asprinio D, Curcin A. Retroperitoneal structures at risk with lumbar pedicle screws: an anatomic and radiographic assessment. Orthop Trans 19951996;19:617.

19. Zindrick MR, Wilste LL, Widell EH, et al. A biomechanical study of intrapeduncular screw fixation in the lumbosacral spine. Clin Orthop Relat Res 1986;203:99-111.

20. Lavaste F. Étude des implants rachidiens. Mémoire de biomechanique. Thesis “Ingeneur”. Paris: Ecole Natl Supér des Arts et Metiers; 1977.

21. Reichle E, Morlock M, Sellenschol K, et al. Definition of pedicle malposition. Primary stability and loosening characteristics of pedicle screws in relation to position: spongious anchoring, cortical anchoring, perforation and malposition. Orthopade 2002;31:402-5.

22. Sim E. Location of transpedicular screws for fixation of the lower thoracic and lumbar spine. Acta Orthop Scand 1993;64:28-32.

The manuscript submitted does not contain information about medical device(s)/drug(s).

No funds were received in support of this work. No benefits in any form have been or will be received from a commercial party related directly or indirectly to the subject of this manuscript. 


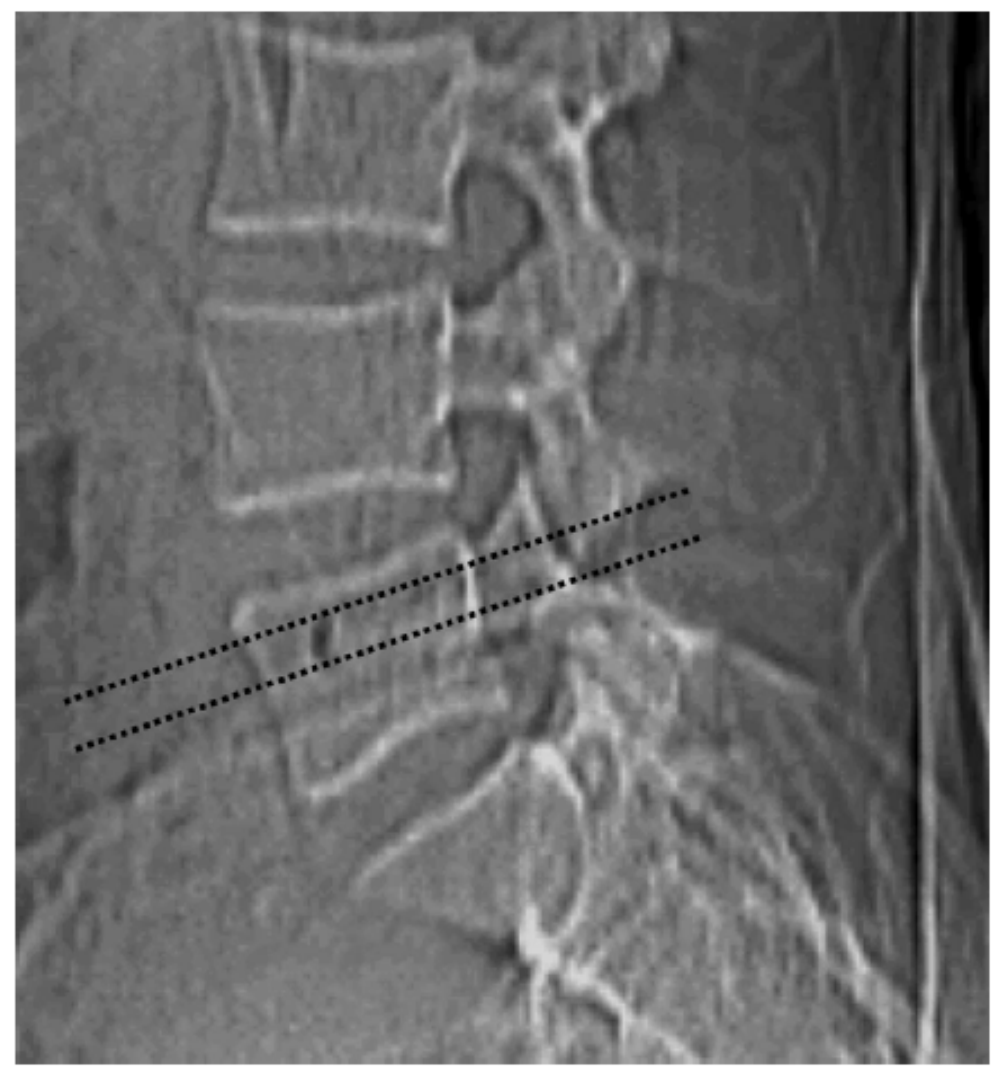

Figure 1. CT slices in the upper part of the pedicle and in the lower part of the pedicle.
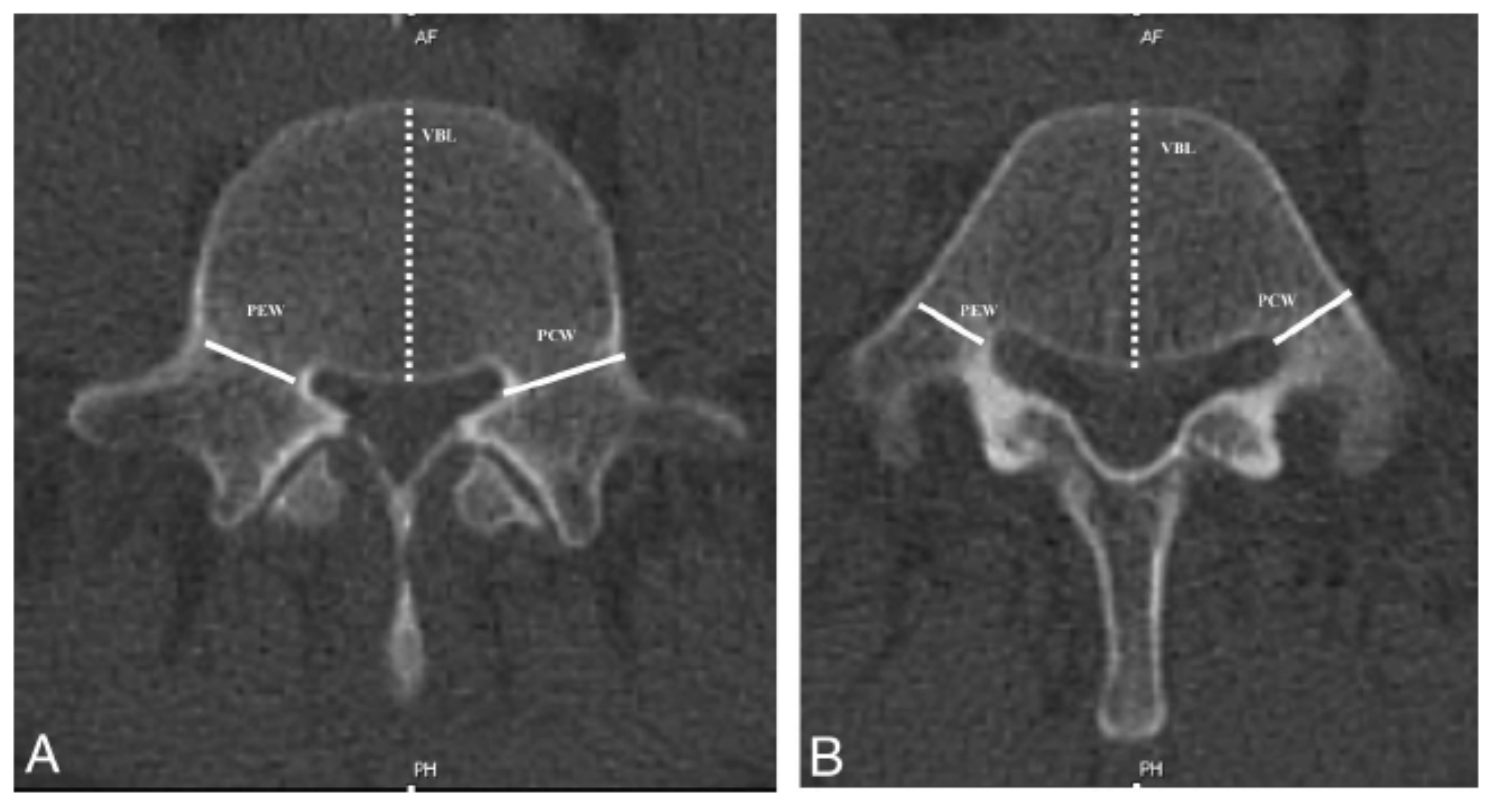

Figure 2. A, Pedicular cortical width (PCW), pedicular endostal width (PEW), and vertebral body length (VBL) in a CT slice in the upper part of the pedicle. $\mathbf{B}$, Pedicular cortical width (PCW), pedicular endostal width (PEW), and vertebral body length (VBL) in a CT slice in the lower part of the pedicle. 

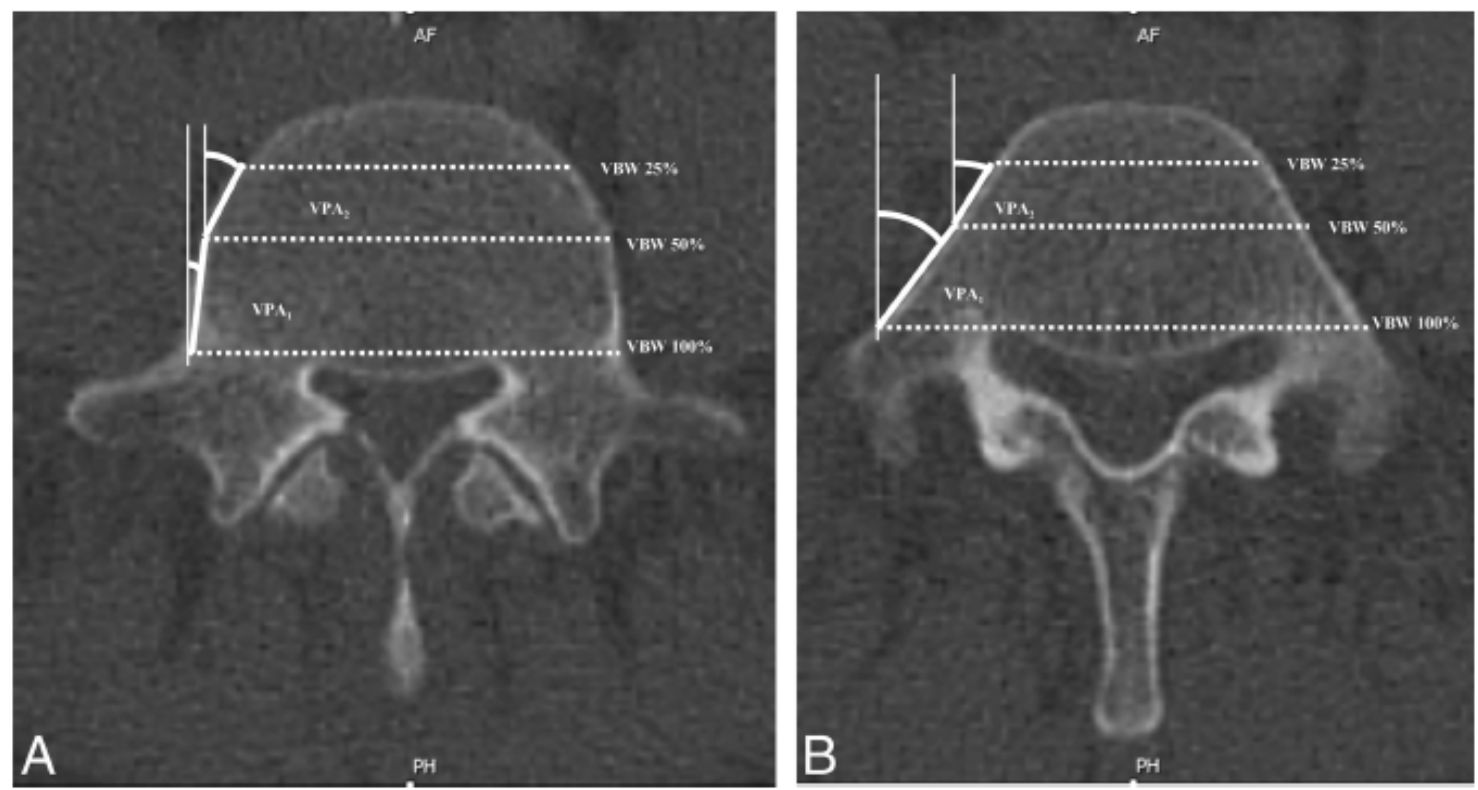

Figure 3. A, Vertebral body width in the posterior part of vertebral body (VBW $100 \%$ ), in the middle of the vertebral body ( $\mathrm{VBW}_{50 \%}$ ), and over the line that passes at $25 \%$ of the vertebral body length $\left(\mathrm{VBW}_{25 \%}\right.$ ), the vertebral perimetral angle proximal $\left(\mathrm{VPA}_{1}\right)$, and distal $\left(\mathrm{VPA}_{2}\right)$ in a CT slice in the upper part of the pedicle. $\mathbf{B}$, Vertebral body width in the posterior part of vertebral body ( $\mathrm{VBW}_{100 \%}$ ), in the middle of the vertebral body ( $\mathrm{VBW}_{50 \%}$ ), and over the line that passes at $25 \%$ of the vertebral body length ( $\mathrm{VBW}_{25 \%}$ ), the vertebral perimetral angle proximal $\left(\mathrm{VPA}_{1}\right)$, and distal $\left(\mathrm{VPA}_{2}\right)$ in a CT slice in the lower part of the pedicle.
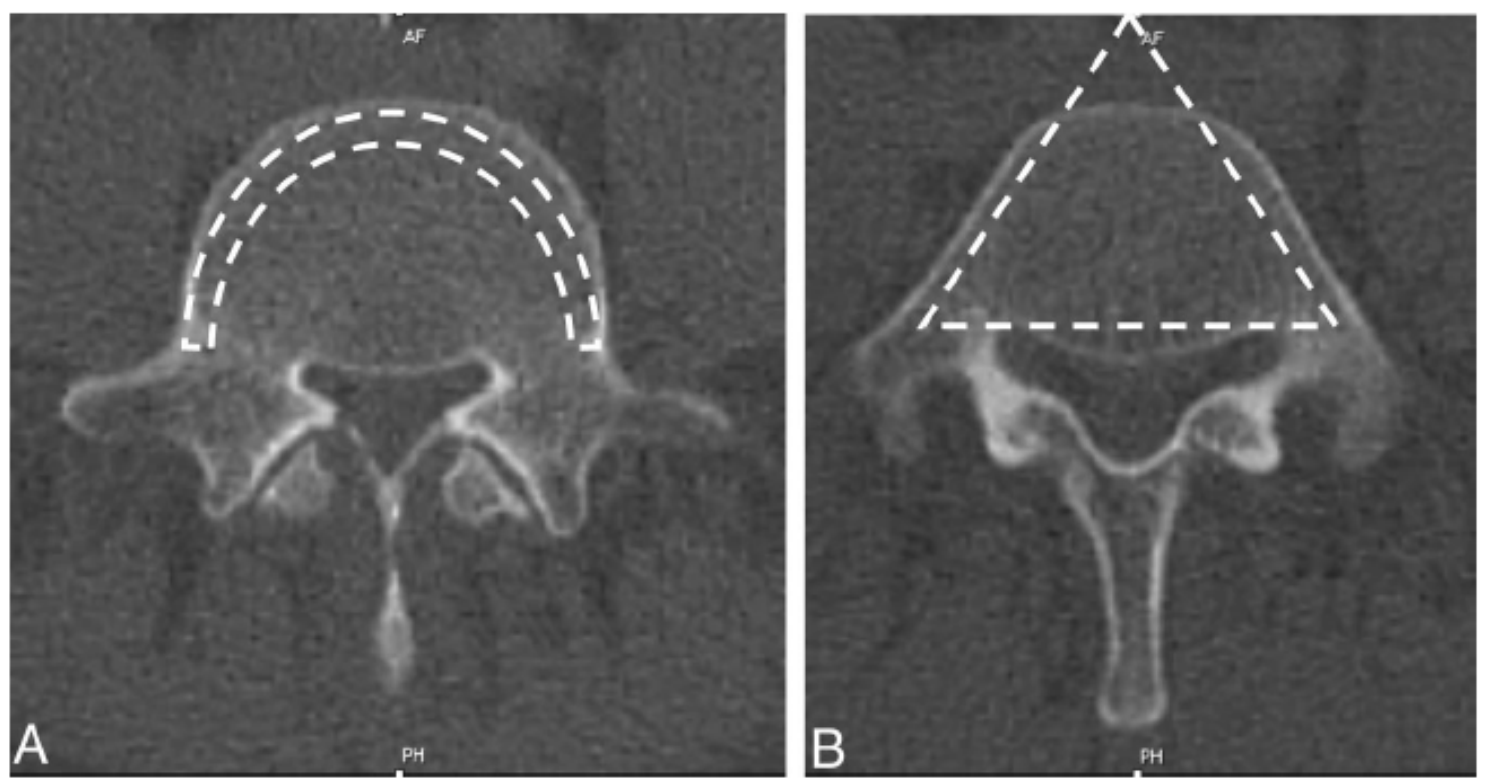

Figure 4. A, Hemispherical shape of L5 in a CT slice in the upper part of the pedicle. B, Triangular shape of L5 in a CT slice in the lower part of the pedicle. 
Table 1. Comparison Between Upper Part and Lower Part in Right and Left Pedicles (Results Are Expressed as Mean Values \pm Standard Deviation)

\begin{tabular}{|c|c|c|c|c|c|c|}
\hline & $\begin{array}{c}\text { Right Pedicle } \\
\text { Upper Part }\end{array}$ & $\begin{array}{c}\text { Right Pedicle } \\
\text { Lower Part }\end{array}$ & $\mathbf{p}$ & $\begin{array}{c}\text { Left Pedicle } \\
\text { Upper Part }\end{array}$ & $\begin{array}{c}\text { Left Pedicle } \\
\text { Lower Part }\end{array}$ & $\mathbf{p}$ \\
\hline PCW & $14.5 \pm 1.9$ & $12.6 \pm 2.4$ & 0.000 & $14.2 \pm 4.4$ & $12.0 \pm 1.6$ & 0.000 \\
\hline PEW & $11.7 \pm 1.7$ & $10.0 \pm 2.3$ & 0.000 & $11.0 \pm 1.6$ & $9.4 \pm 1.7$ & 0.000 \\
\hline PA & $\begin{array}{c}14.2 \text { degrees } \pm \\
4.0 \text { degrees }\end{array}$ & $\begin{array}{c}21.8 \text { degrees } \pm \\
5.1 \text { degrees }\end{array}$ & 0.000 & $\begin{array}{c}12.6 \text { degrees } \pm \\
5.2 \text { degrees }\end{array}$ & $\begin{array}{c}18.3 \text { degrees } \pm \\
5.0 \text { degrees }\end{array}$ & 0.000 \\
\hline
\end{tabular}

PCW indicates pedicular cortical width in millimeter; PEW, pedicular endostal width in millimeter; PA, pedicular angle.

Table 2. Comparison Between Upper Part and Lower Part in Vertebral Body Values (Results Are Expressed as Mean Values \pm Standard Deviation)

\begin{tabular}{|c|c|c|c|}
\hline & Upper Part Through Pedicle & Lower Part Through Pedicle & $P$ \\
\hline VBL & $33.2 \pm 2.9$ & $31.2 \pm 2.5$ & 0.000 \\
\hline VBW $_{100 \%}$ & $54.3 \pm 5.9$ & $59.4 \pm 6.2$ & 0.000 \\
\hline VBW $_{50 \%}$ & $47.6 \pm 5.6$ & $42.8 \pm 5.5$ & 0.000 \\
\hline VBW $_{25 \%}$ & $36.7 \pm 3.9$ & $32.1 \pm 3.4$ & 0.000 \\
\hline VPA $_{1}$ & 9.2 degrees \pm 5.0 degrees & 48.8 degrees \pm 8.0 degrees & 0.000 \\
\hline VPA $_{2}$ & 33.6 degrees \pm 6.3 degrees & 34.1 degrees \pm 6.6 degrees & 0.953 \\
\hline
\end{tabular}

VBL indicates vertebral body length in millimeter; $\mathrm{VBW}_{100 \%}$, vertebral body width at posterior part of vertebral body in millimeter; $\mathrm{VBW}_{50 \%}$, vertebral body width at $50 \%$ of vertebral body in millimeter; $\mathrm{VBW}_{25 \%}$, vertebral body width at $25 \%$ of vertebral body in millimeter; $\mathrm{VPA}_{1}$, vertebral perimetral angle $1 ; \mathrm{VPA}_{2}$, vertebral perimetral angle 2. 